\title{
Effects of inhaled salbutamol in exercising non-asthmatic athletes
}

\author{
C Goubault, M-C Perault, E Leleu, S Bouquet, P Legros, B Vandel, A Denjean
}

\begin{abstract}
Background-Beta-2 agonists such as salbutamol are used, not only by asthmatic athletes to prevent exercise induced asthma, but also by non-asthmatic athletes as a potentially ergogenic agent. We have investigated whether inhaled salbutamol enhances endurance performance in non-asthmatic athletes.

Methods-A prospective double blind, randomised, three way crossover design was used to study the effects of $200 \mu \mathrm{g}$ and $800 \mu \mathrm{g}$ inhaled salbutamol versus a placebo in 12 trained triathletes. The treatments were compared in three identical cycle ergometer sessions at $85 \%$ of the predetermined maximal oxygen uptake. Lung function, endurance time, metabolic parameters (glucose, potassium, lactate, free fatty acid, and glycerol), and psychomotor performance were evaluated.

Results-Neither endurance time nor post-exercise bronchodilation were significantly different between the treatments. Metabolic parameters were affected by exercise but not by treatment. Conclusions-Inhaled salbutamol, even in a high dose, did not have a significant effect on endurance performance in nonasthmatic athletes, although the bronchodilating effect of the drug at the beginning of exercise may have improved respiratory adaptation. Our results do not preclude an ergogenic effect of $\beta_{2}$ agonists given by other routes or for a longer period.

(Thorax 2001;56:675-679)
\end{abstract}

Keywords: asthma; athletes; exercise; inhaled salbutamol; performance enhancers

Many elite athletes have asthma. At the Los Angeles Olympic Games in 1984, 41 of more than 67 athletes with proven exercise induced asthma (EIA) won medals in a wide range of sports including swimming, track events, rowing, and basket ball. ${ }^{1}$ More recently, Weiler et $a l^{2}$ studied the prevalence of asthma among American participants in the 1996 Olympic Games in Atlanta. Of the 699 athletes who completed the questionnaire, $107(15.3 \%)$ reported a diagnosis of asthma, 97 (13.9\%) had used an asthma medication at some time in the past, and $73(10.4 \%)$ were using an asthma medication during the Games. Whether the prevalence of asthma is higher in athletes than in the general population remains controversial. Several studies found an increase in the prevalence of asthma symptoms or nonspecific bronchial hyperreactivity in cross country skiers or players of American football. ${ }^{34}$ However, a retrospective study of 1282 Finnish competitive athletes by Kujala et $a \bar{l}$ found no evidence that high levels of physical activity had a significant influence on the prevalence of asthma.

In European countries many athletes use $\beta_{2}$ agonists during sports competitions, claiming they need the treatment to prevent EIA. In some countries short acting inhaled $\beta_{2}$ agonists are authorised during international competitions. In France a diagnosis of EIA by a physician is required, yet $\beta_{2}$ agonists are the drugs most commonly identified by urine tests performed during sports competitions, particularly bicycle races. Although inhaled $\beta_{2}$ agonists are generally used for their bronchodilating effect, we know that oral $\beta_{2}$ agonists also increase muscle mass by stimulating protein anabolism and they also increase the metabolism of lipids and carbohydrates. ${ }^{6-8}$ Furthermore, studies done in the 1980 s identified effects of oral $\beta_{2}$ agonists on the central nervous system effects consistent with antidepressant activity. ${ }^{9}$ These findings explain why $\beta_{2}$ agonists are widely used by athletes in search of an ergogenic effect. Whether such an effect exists remains doubtful; some studies found no beneficial effects of inhaled salbutamol or salmeterol in various doses on physical performance during exercise in normal subjects ${ }^{10-12}$ or asthmatics, ${ }^{13-15}$ but Bedi et $a l^{16}$ and Signorile et $a l^{17}$ reported a significant increase in endurance time or maximal power of exercise in normal subjects after $180 \mu \mathrm{g}$ inhaled salbutamol.

In this study we have evaluated the effects of $200 \mu \mathrm{g}$ and $800 \mu \mathrm{g}$ inhaled salbutamol (the standard and maximal doses used in asthmatic patients, respectively) on endurance time in 12 non-asthmatic trained cyclists exercising at $85 \%$ of their maximal aerobic power. We also looked for effects of salbutamol on energy metabolism and central nervous system function.

\section{Methods}

SUBJECTS

Of the 13 subjects entered into the study, one was excluded because urine tests showed the presence of cannabinoids. All the subjects read and signed an informed consent document before the tests, and the appropriate ethics committee approved the study. All 12 subjects were competitive triathletes screened by medical history, physical examination, 12-lead electrocardiography, baseline pulmonary function tests, and standard laboratory parameters. 
Table 1 Baseline characteristics of study subjects

\begin{tabular}{|c|c|c|c|c|c|c|c|}
\hline Subject & Age (years) & $\begin{array}{l}\text { Height } \\
(\mathrm{cm})\end{array}$ & Weight $(\mathrm{kg})$ & $F E V_{1}(l)$ & $\begin{array}{l}\dot{V} \mathrm{O}_{2} \max \\
(\mathrm{ml} / \mathrm{kg} / \mathrm{min})\end{array}$ & $\begin{array}{l}\text { Pmax } \\
\text { (watts) }\end{array}$ & $H R \max (b p m)$ \\
\hline 1 & 26 & 180 & 72 & 4.80 & 57.5 & 388 & 188 \\
\hline 2 & 24 & 179 & 69 & 5.24 & 52.2 & 335 & 184 \\
\hline 3 & 20 & 175 & 62 & 4.44 & 59.8 & 340 & 196 \\
\hline 4 & 23 & 176 & 63 & 4.60 & 57.5 & 359 & 203 \\
\hline 5 & 23 & 176 & 68 & 5.28 & 69.7 & 400 & 178 \\
\hline 6 & 23 & 178 & 70 & 4.68 & 60.6 & 350 & 194 \\
\hline 7 & 25 & 182 & 82 & 5.12 & 51.2 & 380 & 181 \\
\hline 8 & 26 & 183 & 75 & 5.36 & 51 & 380 & 181 \\
\hline 9 & 21 & 173 & 65 & 4.92 & 57.9 & 320 & 174 \\
\hline 10 & 22 & 175 & 63 & 4.64 & 59 & 330 & 190 \\
\hline 11 & 25 & 169 & 60 & 4.36 & 60.7 & 302 & 194 \\
\hline 12 & 22 & 175 & 66 & 4.28 & 58 & 325 & 192 \\
\hline Mean (SD) & $23(2)$ & $177(4)$ & $67.9(6.2)$ & $4.81(0.37)$ & $57.9(5.1)$ & $350(30)$ & $188(8)$ \\
\hline
\end{tabular}

$\mathrm{FEV}_{1}=$ forced expiratory volume in 1 second $; \dot{\mathrm{V}}_{2} \max =$ maximal oxygen uptake; Pmax = maximal aerobic power; HRmax = maximal heart rate.

None were smokers and none had a history of atopy or of asthma or other cardiorespiratory disorders. During the screening visit each subject underwent an incremental maximal aerobic capacity test on a cycle ergometer to determine maximal oxygen consumption ( $\dot{\mathrm{V}}_{\mathrm{O}_{2}} \mathrm{max}$ ) and maximal aerobic power and were familiarised with psychometric tests. Table 1 summarises the baseline characteristics of the subjects.

\section{STUDY DESIGN}

A prospective double blind, randomised, threeway crossover design was used to compare two dose levels of salbutamol $(200 \mu \mathrm{g}$ and $800 \mu \mathrm{g})$ and a placebo, administered by inhalation during three identical cycle ergometer sessions performed at least 48 hours apart, within a period of no more than 3 weeks (fig 1 ).

Each subject performed three identical constant load exercise sessions on a cycle ergometer at $85 \%$ of the predetermined maximal aerobic power until exhaustion. The maximal endurance time was recorded. One session was done with salbutamol $200 \mu \mathrm{g}$, one with salbutamol $800 \mu \mathrm{g}$, and one with the placebo; all treatments were given by inhalation in random order.

A venous catheter was inserted into an antecubital vein on arrival at the laboratory. After a 15 minute rest, blood pressure and heart rate were measured and samples of venous blood and urine were collected. Psychometric and lung function tests were performed and the randomly assigned treatment was given. Ten minutes later lung function tests and

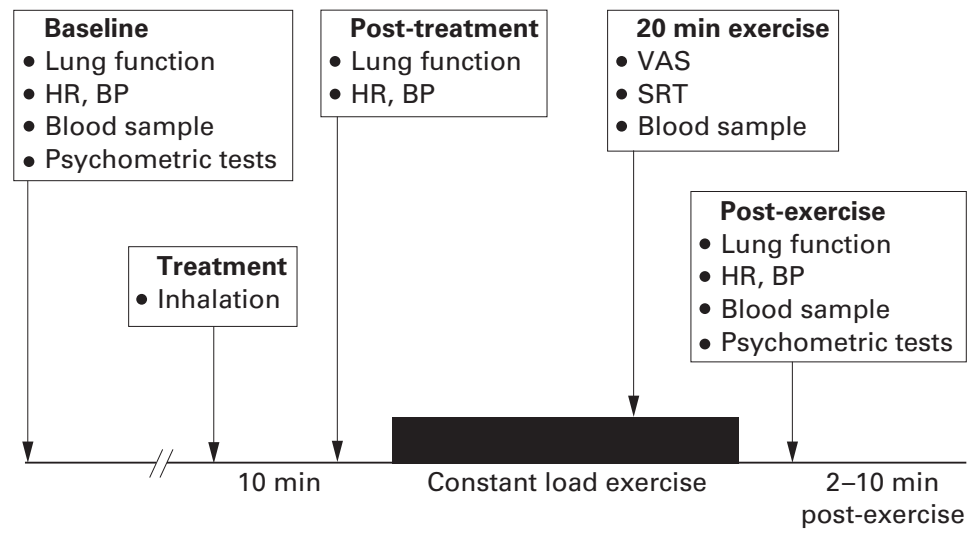

Figure 1 Protocol design. $H R=$ heart rate, $B P=$ blood pressure, VAS $=$ visual analogue scale, $S R T=$ simple reaction test. measurements of blood pressure and heart rate were repeated before starting exercise. Twenty minutes after the start of the exercise, the subject completed visual analogue scales to quantify sensations of dyspnoea and muscle fatigue. A simple reaction test (see below) was then performed and a venous blood sample was collected. The subject was encouraged to exercise until exhaustion. From the second to the tenth minute after the end of collection of the exercise blood sample, the psychometric and lung function tests were repeated. The main criterion for an ergogenic effect of salbutamol was an increase in endurance time - that is, in the time between the beginning and the end of the exercise compared with the placebo.

All exercise sessions were performed on an electronically braked cycle ergometer (Bosch Erg 602, Dimeq, Berlin, Germany). During the screening visit $\dot{\mathrm{V}}_{2} \mathrm{max}$ was determined as follows. After a 3 minute warm up at $60 \mathrm{~W}$ the load was increased $(30 \mathrm{~W} / \mathrm{min})$ until the subject was unable to continue. The subject breathed through a face mask (Hans Rudolph, Kansas City, MO, USA) and expired gases were analysed breath-by-breath using an automated system (CPX/D, Medical Graphics, St Paul, MN, USA). Inspired and expired gas flows were measured using a pneumotachometer (type 3, Hans Rudolph, Kansas City, MO, USA). Minute ventilation, oxygen consumption $\left(\dot{\mathrm{V}}_{2}\right)$, and carbon dioxide production $\left(\dot{\mathrm{V}} \mathrm{CO}_{2}\right)$ were averaged over the last $15 \mathrm{sec}-$ onds of each minute. Criteria for $\dot{\mathrm{V}}_{2} \max$ determination were attainment of the age predicted maximal heart rate (220-age bpm), a respiratory exchange ratio of $>1.1$, and stabilisation of $\dot{\mathrm{V}}_{2}$ despite a further increase in workload ( $\mathrm{T}$ W Storer). The system was calibrated before each test using a calibrated 31 syringe and appropriate gas cylinders.

During the constant load exercise tests the subjects exercised at $85 \%$ of their maximal aerobic power determined during the screening visit. During these three tests ventilatory measurements $\left(\dot{\mathrm{V}}_{\mathrm{E}}, \dot{\mathrm{V}}_{2}, \dot{\mathrm{V}} \mathrm{CO}_{2}\right.$ ) were continuously monitored using the same respiratory circuit (CPX system) as for $\dot{\mathrm{V}}_{2} \max$ determination. Heart rate was monitored and recorded continuously using ECG leads connected to the CPX computer. 
Table 2 Mean (SD) forced expiratory volume in 1 second (FEV ) during the three sessions before treatment, 10 minutes after treatment, and after exercise

\begin{tabular}{llll}
\hline Treatment & $F E V_{1}$ (litres) & & \\
\cline { 2 - 4 } & Baseline & 10 min after treatment & After exercise \\
\hline S200 & $4.51(0.40)$ & $4.74(0.42)^{\star}$ & $4.73(0.34)^{\star}$ \\
S800 & $4.47(0.39)$ & $4.68(0.43)^{\star}$ & $4.78(0.41)^{\star}$ \\
Placebo & $4.46(0.32)$ & $4.45(0.32)$ & $4.63(0.35)^{\star}$ \\
\hline
\end{tabular}

S200 = salbutamol $200 \mu \mathrm{g} ; \mathrm{S} 800=$ salbutamol $800 \mu \mathrm{g}$.

${ }^{\star} \mathrm{p}<0.05$ versus baseline.

The blood samples were used to measure plasma concentrations of glucose, lactate, glycerol, and free fatty acids.

Lung function testing involved use of a computerised calibrated system (Sensormedics 2200, Bilthoven, Netherlands) to plot maximal expiratory flow-volume curves which were used to measure forced vital capacity (FVC) and forced expiratory volume in 1 second $\left(\mathrm{FEV}_{1}\right)$. A 10 point visual analogue scale (VAS) placed on the handlebars was completed by the subjects to assess sensations of dyspnoea and muscle fatigue.

Psychometric VAS and psychomotor performance tests were administered in the same order during each session, before and after exercising. The subjects received familiarisation with the VAS and performance tests during the screening visit. The VAS comprised the 16 bipolar analogue scales of the Bond and Lader mood rating scale. ${ }^{18}$ Three mood factors were assessed: attention and vigilance, feeling of well being, and sense of relaxation. Psychomotor performance was assessed using four tests: the choice reaction time, the simple reaction test, the tapping test, and the arithmetic calculation test. The choice reaction time (CRT) was used to assess sensory motor performance. Its various components (motor reaction time (MRT), recognition reaction time (RRT)) and the total reaction time (TRT) were determined using the Leeds psychomotor tester. The subjects were asked to extinguish one of six LED lights illuminated at random by pushing the appropriate button. The score was recorded as the mean reaction time to 50 stimuli. In the simple reaction test (SRT) the subjects were asked to press a button each time they heard an auditory stimulus; the auditory stimuli were of various lengths and amplitudes and were delivered randomly. The score was the mean reaction time to 30 stimuli. The tapping test (TAP) was performed by asking subjects to tap with the spike of a stylus as quickly as possible for 30 seconds. The score was the mean number of taps per second. Finally, in the arithmetic calculation test (Pauli's test) the subjects had to add single digit numbers as quickly and accurately as possible over a 3 minute period. Performance was expressed as the number of correct answers.

The treatments were administered as follows: two puffs of salbutamol or placebo were introduced into a spacer (Volumatic, Glaxo) using metered dose inhalers. Subjects then took two slow inspirations from the spacer, from residual capacity to total lung capacity, at an interval of 1 minute. This procedure was repeated four times for a total of eight puffs.
The three treatments were $800 \mu \mathrm{g}$ salbutamol (S800), $200 \mu \mathrm{g}$ salbutamol + placebo (S200), and placebo alone. To ensure blinding the technician who gave the random order treatments was not involved in the other parts of the protocol.

In each subject plasma separated from the blood collected towards the end of each exercise period was frozen for a subsequent salbutamol assay. In six subjects urine was collected during the 4 hours after each exercise period for a salbutamol assay. All salbutamol assays were done using reverse phase high performance liquid chromatography with amperometric detection. ${ }^{19}$ This method involves combined liquid-liquid extraction and liquid-solid extraction using OASIS millipore cartridges for sample clean up, followed by separation of salbutamol and the internal standard from interfering compounds on a reversed phase column. The interassay coefficients of variation at salbutamol concentrations of 1.0 and $6.0 \mathrm{ng} / \mathrm{ml}$ were $8.4 \%$ and $7.2 \%$, respectively $(\mathrm{n}=12)$. The detection limit was $0.3 \mathrm{ng} / \mathrm{ml}$ in $1.0 \mathrm{ml}$ of plasma or urine.

\section{ANALYSIS OF DATA}

Data were analysed using repeated measures analysis of variance with treatment and time as the factors (Statview Abbacus Concept, Berkeley, CA, USA). Where appropriate, pairwise comparisons were tested using Bonferroni's test. $\mathrm{p}$ values of 0.05 or less were considered statistically significant.

\section{Results}

Mean (SD) maximal endurance times were similar after inhalation of salbutamol or placebo (23 $\min 31 \mathrm{~s} \mathrm{(4} \mathrm{min} 56 \mathrm{~s}$ ) with S200, 21 $\min (3 \mathrm{~min} 45 \mathrm{~s}$ ) with $\mathrm{S} 800$, and $23 \mathrm{~min} 18 \mathrm{~s}(5$ min $8 \mathrm{~s}$ ) with placebo).

At rest, treatment significantly increased the heart rate $(\mathrm{p}=0.006)$ and systolic blood pressure $(p=0.02)$ as follows: heart rate, 68 (14) bpm $v 59$ (8) bpm with S200, 64 (10) bpm $v 55$ (6) bpm with S800, and 60 (9) bpm $v 58$ (5) bpm with placebo; systolic blood pressure 127 (9) $\mathrm{mm} \mathrm{Hg}$ v 121 (7) $\mathrm{mm} \mathrm{Hg}$ with S200, 123 (7) $\mathrm{mm} \mathrm{Hg} v 118$ (8) $\mathrm{mm} \mathrm{Hg}$ with S800, and 125 (9) $\mathrm{mm} \mathrm{Hg} v$ 120 (7) $\mathrm{mm} \mathrm{Hg}$ with placebo. However, heart rate at exhaustion was similar across the three sessions: 185 (7) bpm with S200, 185 (9) bpm with S800, and 185 (8) bpm with placebo.

As shown in table 2, post-inhalation $\mathrm{FEV}_{1}$ values were higher after salbutamol while postexercise $\mathrm{FEV}_{1}$ values were similar with the three treatments.

Sensations of dyspnoea and muscle fatigue evaluated by the VAS increased during exercise with no significant differences across the treatments. The dyspnoea VAS score rose from 6.7 (2.3) to 7.9 (1.4) with S200, from 6.1 (1.7) to 7.5 (1.9) with $S 800$, and from 6.9 (1.6) to 8.3 (0.8) with placebo ( $\mathrm{p}=0.0025$ for the time factor and 0.27 for the treatment factor). The muscle fatigue VAS score increased from 7.4 (1.5) to 8.1 (1.1) with S200, from 6.6 (1.5) to 7.9 (1.5) with S800, and from 7.2 (1.4) to 9.5 
Table 3 Psychometric tests before and after exercise with salbutamol $200 \mu \mathrm{g}$ (S200), salbutamol $800 \mu \mathrm{g}$ (S800), or placebo

\begin{tabular}{llll}
\hline & $S 200$ & $S 800$ & Placebo \\
\hline CRT & $497(38)$ & $491(48)$ & $493(44)$ \\
$\quad$ Baseline & $502(47)$ & $497(51)$ \\
$\quad$ Post-exercise & $798(49)$ & $7(0.7)$ & $7(0.5)$ \\
$\begin{array}{l}\text { Tapping test } \\
\quad \text { Baseline }\end{array}$ & $7(0.7)$ & $7(0.6)$ & $7(0.6)$ \\
$\quad \begin{array}{l}\text { Post-exercise } \\
\text { Pauli test }\end{array} \quad 176(25)$ & $179(25)$ \\
$\quad$ Baseline & $177(28)$ & $191(22)$ & $194(21)$ \\
$\quad$ Post-exercise & $192(23)$ & & \\
\hline
\end{tabular}

Data are expressed as mean (SD).

Choice reaction time (CRT) is expressed in milliseconds, tapping test score as the number of taps per second, and the Pauli test (arithmetic calculation test) is expressed as the number of correct additions in 3 minutes.

The only significant differences are between pre-exercise and post-exercise Pauli test scores with all three treatments $(\mathrm{p}<0.01)$

(3.4) with placebo ( $\mathrm{p}=0.005$ for the time factor and 0.15 for the treatment factor).

Post-exercise values of minute ventilation (VE) and oxygen uptake were similar with the three treatments. During the second minute of exercise, in contrast, $\mathrm{VE}$ was significantly higher after salbutamol than after placebo (57.5 (8.4) $1 / \mathrm{min}$ with S200, 60.2 (6.4) $1 / \mathrm{min}$ with $\mathrm{S} 800 v 51.5 \quad(10.2) 1 / \mathrm{min}$ with placebo; $\mathrm{p}=0.04)$.

Overall, salbutamol had no effect on the VAS scores and performance indicators. The SRT was significantly slower during exercise with all three treatments $(\mathrm{p}<0.001)$ : baseline reaction times were 217 (11) ms with S200, 215.5 (10) $\mathrm{ms}$ with S800, and 215 (8) $\mathrm{ms}$ with placebo; reaction times during exercise were 277 (18) ms with S200, 310 (24) ms with S800, and 282 (14) $\mathrm{ms}$ with placebo and these values returned to a level slightly above baseline after exercise. The results for the CRT, $\mathrm{TAP}$, and arithmetic calculation tests are given in table 3. As evaluated by the Bond and Lader VASs, salbutamol did not induce significant changes in alertness, contentedness, or calmness at any time before or after exercise (results not shown).

None of the laboratory parameters measured during exercise were affected by salbutamol. For clarity, table 4 shows only the values measured at rest and at the end of exercise. Exercise caused significant increases in blood glucose, lactate, glycerol, and free fatty acids; plasma potassium increased but remained within the normal range.

Plasma levels of salbutamol were first measured in samples taken during the S800 trial: at the end of exercise the value was extremely low $(2.22(0.47) \mathrm{ng} / \mathrm{ml}$; range 0.50 $5.30 \mathrm{ng} / \mathrm{ml} ; \mathrm{n}=11)$. After $\mathrm{S} 800$ the salbutamol level in the 4 hour post-exercise urine specimen was $317.4(0.67) \mathrm{ng} / \mathrm{ml}$ (range $110-519 \mathrm{ng} / \mathrm{ml}$; $\mathrm{n}=6$ ). Because plasma salbutamol levels were very low after the highest salbutamol dose, levels after the lower dose were not determined.

\section{Discussion}

We found no ergogenic effects of $200 \mu \mathrm{g}$ or $800 \mu \mathrm{g}$ salbutamol inhaled 10 minutes before the beginning of a cycle ergometer session at $85 \%$ maximal aerobic power in highly trained, normal athletes. Moreover, the doses of inhaled salbutamol used in our study had no significant effects on plasma levels of glucose and lipids or on central nervous system function. The bronchodilation induced by salbutamol was modest in magnitude, being significant only at the beginning of exercise.

This is the first study of the effects of large doses of inhaled salbutamol, not only on performance indicators and lung function but also on metabolic and central nervous system parameters in a group of highly trained athletes. Previous investigations used different exercise protocols and $\beta_{2}$ agonist doses from those used in our study. Only two studies conducted with $200 \mu \mathrm{g}$ inhaled salbutamol found evidence of an ergogenic effect, which consisted in an increase in endurance time during square submaximal exercising. ${ }^{16}{ }^{17}$ Our results are in agreement with the larger group of studies that failed to demonstrate an ergogenic effect with this dose ${ }^{101120}$ or higher doses $(360 \mu \mathrm{g}$ and $400 \mu \mathrm{g})$ during various types of exercise. $^{21} 22$ Similarly, brief nebulisations of salbutamol or salmeterol failed to demonstrate ergogenic effects. ${ }^{23-25}$ In contrast, there have been reports that albuterol given orally in a dose of $16 \mathrm{mg} /$ day for 9 weeks increased gains in quadriceps muscle strength and that various $\beta$ agonists enhanced skeletal muscle anabolism. ${ }^{26-28}$

As in previous studies, salbutamol had a significant bronchodilating effect in our normal subjects. ${ }^{22}{ }^{23}$ At the beginning of exercise this effect may improve adaptation to the increased work of breathing by reducing respiratory resistance. Consistent with this possibility, salbutamol increased minute ventilation at the beginning of exercise and decreased the sensation of dyspnoea. Post-exercise VAS scores showed more severe dyspnoea after placebo inhalation than after salbutamol inhalation.

Salbutamol had the expected effects on blood pressure and heart rate which cannot be considered beneficial during exercise. We found no effects of inhaled salbutamol on blood glucose or lipid levels, nor did serum potassium levels move outside the normal range. This stable metabolic profile in our subjects, despite the many known metabolic effects

Table 4 Mean (SD) metabolic parameters at rest and at the end of exercise with salbutamol $200 \mu \mathrm{g}$ (S200), salbutamol 800 $\mu \mathrm{g}$ (S800), or placebo

\begin{tabular}{|c|c|c|c|c|c|c|}
\hline & \multicolumn{3}{|l|}{ Rest } & \multicolumn{3}{|l|}{ Exercise } \\
\hline & $S 200$ & $S 800$ & Placebo & $S 200$ & $S 800$ & Placebo \\
\hline Glucose $(\mathrm{mmol} / \mathrm{l})$ & $4.6(0.6)$ & $4.7(1.0)$ & $4.7(0.5)$ & $6.5(1.6)$ & $7.0(1.4)$ & $7.1(1.7)$ \\
\hline Lactate $(\mathrm{mmol} / \mathrm{l})$ & $1.9(0.7)$ & $1.8(0.4)$ & $2.0(0.6)$ & $11.0(2.9)$ & $11.2(3.7)$ & $10.5(3.6)$ \\
\hline Glycerol (mg/l) & $28(6)$ & $19(3)$ & $21(3)$ & $36(5)$ & $38(5)$ & $36(5)$ \\
\hline Free fatty acid $(\mathrm{mmol} / \mathrm{l})$ & $0.22(0.08)$ & $0.14(0.03)$ & $0.09(0.01)$ & $0.26(0.05)$ & $0.25(0.07)$ & $0.29(0.05)$ \\
\hline Potassium $(\mathrm{mmol} / \mathrm{l})$ & $3.8(0.4)$ & $3.9(0.3)$ & $3.9(0.3)$ & $4.5(0.3)$ & $4.3(0.5)$ & $4.5(0.6)$ \\
\hline
\end{tabular}

For each parameter the value at exercise was significantly higher than at rest $(\mathrm{p}<0.001)$. 
of salbutamol, ${ }^{7}$ is probably ascribable to the fact that inhaled salbutamol has little effect on systemic parameters.

Antidepressant effects of salbutamol have been reported in animal models $\mathrm{s}^{29}$ and humans $\mathrm{s}^{30}$ and are probably ascribable to an increase in serotoninergic activity. Consequently, when we designed this study we hypothesised that salbutamol may have psychostimulant effects associated with better tolerance to exercise. Our results do not support this hypothesis: none of the mood evaluation or psychomotor performance tests used in our study had any significant changes after salbutamol inhalation at rest or after exercising.

At the end of the exercise period-that is, 40-50 minutes after salbutamol inhalationthe plasma salbutamol level was extremely low $(0.5-9.6 \mathrm{ng} / \mathrm{ml})$ with the $800 \mu \mathrm{g}$ dose. With the same high dose, salbutamol levels in the 4 hour post-exercise urine specimen varied from 200 to $700 \mathrm{ng} / \mathrm{ml}$, and the total amount of salbutamol recovered was less than $100 \mu \mathrm{g}$. These values are very low. Salbutamol doses given in asthma are usually far smaller than $800 \mu \mathrm{g}$ so they would probably result in negative urine tests should they be inhaled by an athlete during a competition, and positive urine tests probably indicate use of a systemic route and/or of extremely high doses. Yet, the French antidoping laboratory considers that urinary concentrations of salbutamol above $1000 \mathrm{ng} /$ $\mathrm{ml}$ can preclude oral absorption of the drug for purposes other than the treatment or prevention of asthma

In conclusion, our study failed to demonstrate significant enhancement of endurance performance and metabolic or psychostimulant effects of large doses of inhaled salbutamol in highly trained non-asthmatic cyclists. However, salbutamol had a slight but significant bronchodilator effect which may be sufficient to improve respiratory adaptation at the beginning of exercise. It is unlikely that the widespread use of salbutamol by athletes is driven by the weak effects of inhaled salbutamol. We believe our data suggest that most non-asthmatic salbutamol users take the drug orally or by injection, probably for protracted periods. This pattern of use may be associated with ergogenic and metabolic effects. Policies aimed at restricting the use of performance enhancers should reserve inhaled $\beta$ agonists for athletes with documented asthma.

This study was supported by a grant from "Agence du Médicament".

1 Voy RO. The US Olympic Committee experience with exercise-induced bronchospasm. Med Sci Exerc 1986;18:328-30.
2 Weiler JM, Layton T, Hunt M. Asthma in United States Olympic athletes who participated in the 1996 Summer Olympic athletes who participated in the 1996
Games. F Allergy Clin Immunol 1998;102:722-6.

3 Larsson K, Ohlsen P, Larsson L, et al. High prevalence of asthma in cross-country skiers. BMF 1993;307:1326-9.

4 Heir T, Oseid S. Self-reported asthma and exercise-induced asthma symptoms in high level competitive cross-country skiers. Scand f Med Sci Sports 1994;4:128-33.

5 Kujala UM, Sarna S, Kaprio J, et al. Asthma and other pulmonary diseases in former elite athletes. Thorax 1996;51: monary

6 Lafontan M, Berlan M, Prud'hon M. Les agonistes bêta-adrénergiques. Mécanismes d'action: lipomobilisation et anabolisme. Reprod Nutr Dévelop 1988;28:61-84.

7 Price AH, Clissold SP. Salbutamol in the 1980s. A reappraisal of its clinical efficacy. Drugs 1989;38:77-122.

8 Martineau L, Horan MA, Rothwell NJ, et al. Salbutamol, a $\beta_{2}$ adrenoceptor agonist, increases skeletal muscle strength in young men. Clin Sci 1992;83:615-21.

9 Belmaker RH, Lerer B, Zohar J. Salbutamol treatment of Belmaker RH, Lerer B, Zohar J. Salbutamol treatment of
depression. Adv Biochem Psychopharmacol 1982;32:181-93.

10 Morton AR, Papalia SM, Fitch KD. Is salbutamol ergogenic? The effects of salbutamol on physical performance in high-performance nonasthmatic athletes. Clin $\mathcal{f}$ Sports Med 1992;2:93-7.

11 Meeuwisse WH, McKenzie DC, Hopkins SR, et al. The effect of salbutamol on performance in elite nonasthmatic athletes. Med Sci Sports Exerc 1992;24:1161-6.

12 Fleck SJ, Lucia A, Stroms WW, et al. Effects of acute inhalation of albuterol on submaximal and maximal $\mathrm{VO}_{2}$ and tion of albuterol on submaximal and maximal

13 Schmidt A, Diamant B, Bundgaard A, et al. Ergogenic effect of inhaled $\beta 2$-agonists in asthmatics. Int $\mathcal{F}$ Sports Med 1988; 9:338-40

14 Freeman W, Packe GE, Cayton RM. Effect of nebulised salbutamol on maximal exercise performance in men with mild asthma. Thorax 1989;44:942-7.

15 Robertson W, Simkins J, O'Hickey SP, et al. Does single dose salmeterol affect exercise capacity in asthmatic men. Eur Respir f 1994;7:1976-84

16 Bedi JF, Gong H Jr, Horvath SM. Enhancement of exercise performance with inhaled albuterol. Can $\mathcal{F}$ Sport Sci 1988; 13:144-8.

17 Signorile JF, Kaplan TA, Applegate B, et al. Effects of acute inhalation of the bronchodilator, albuterol, on power output. Med Sci Sports Exerc 1992;24:638-42.

18 Bond $\mathrm{A}$, Lader $\mathrm{M}$. The use of analogue scales in rating subjective feelings. Br 7 Psychol 1974;47:211-8.

19 Tan YK, Soldin SJ. Determination of salbutamol in human serum by reversed-phase high performance liquid chromatography with amperometric detection. I Chromatogr 1984; 311:311-7.

20 Morton AR, Papalia SM, Fitch KD. Changes in anaerobic power and stength performance after inhalation of salbutamol in non asthmatic athletes. Clin F Sport Med 1993;3:1419

21 Lemmer JT, Fleck SJ, Wallach JM, et al. The effects of albuterol on power output in non-asthmatic athletes. Int $\mathcal{F}$ Sports Med 1995;16:243-9.

22 Norris SR, Petersen SR, Jones RL. The effect of salbutamol on performance in endurance cyclists. Eur f Appl Physiol 1996;73:364-8.

23 Heir T, Stemshaug H. Salbutamol and high-intensity treadmill running in nonasthmatic highly conditioned athletes. Scand F Med Sci Sports 1995;5:231-6.

24 Morton AR, Joyce K, Papalia SM, et al. Is salmeterol ergogenic? Clin $\mathcal{F}$ Sport Med 1996;6:220-5.

25 Carlsen KH, Ingjer F, Kirkegaard H, et al. The effect of inhaled salbutamol and salmeterol on lung function and endurance performance in healthy well-trained athletes. Scand $\mathcal{F}$ Med Sci Sports 1997;7:160-5.

26 Broadley KJ, Spencer PSJ. Muscling in on salbutamol. Lancet 1993;341:313.

27 Maltin CA, Delday MI, Watson JS, et al. Clenbuterol, a $\beta$-adrenoceptor agonist, increases relative muscle strngth in $\beta$-adrenoceptor agonist, increases relative mu
orthopedic patient. Clin Sci 1993;84:651-4.

28 Caruso JF, Signorile JF, Perry AC, et al. The effects of albuterol and isokinetics on the quadriceps muscle group. Med Sci Sports Exerc 1995;27:1471-6.

29 Cowen PJ, Graham-Smith DG, Green AR, et al. Betaadrenoceptor agonists enhance 5-hydroxy tryptaminemediated behavioural responses. Br F Pharmacol 1982;76: 265-70.

30 Erdo L, Kiss B, Rosdy B. The effect of salbutamol on the cerebral levels, uptake and turnover of serotonin. Eur $\mathcal{F}$ Pharmacol 1982;78:357-61. 